\title{
Solution for Blood Fraction Modification
}

National Cancer Institute

\section{Source}

National Cancer Institute. Solution for Blood Fraction Modification. NCI Thesaurus. Code C149902.

Liquid sterile preparation consisting of a solution intended for use in extracorporeal

modification of a blood fraction that is returned to the patient following modification. 